\title{
The biology and function of extracellular vesicles in nasopharyngeal carcinoma (Review)
}

\author{
BO YOU ${ }^{1 *}$, YING SHAN $^{1 *}$, LILI BAO $^{1}$, JING CHEN $^{1}$, LIU YANG $^{2}$, QICHENG ZHANG ${ }^{1}$, \\ WEI ZHANG ${ }^{1}$, ZHENXIN ZHANG $^{1}$, JIE ZHANG ${ }^{1}$, SI SHI $^{1}$ and YIWEN YOU ${ }^{1}$ \\ Departments of ${ }^{1}$ Otorhinolaryngology, Head and Neck Surgery, and ${ }^{2}$ Neurosurgery, \\ Affiliated Hospital of Nantong University, Nantong, Jiangsu 226001, P.R. China
}

Received August 12, 2017; Accepted October 2, 2017

DOI: 10.3892/ijo.2017.4202

\begin{abstract}
Extracellular vesicles are a heterogeneous group of membrane-enclosed vesicles, which play an important role in intercellular communication. Increasing number of studies have shown that tumor-derived extracellular vesicles might be involved in the transfer of oncogenic cargo (proteins, lipids, messenger RNA, microRNA, non-coding RNAs and DNA) through which cancer cells could shape the tumor microenvironment and influence tumor progression. Nasopharyngeal carcinoma-derived extracellular vesicles have also reported to facilitate tumor proliferation, metastasis and immune escape. Moreover, nasopharyngeal carcinoma-derived extracellular vesicles might serve as biomarkers for early diagnosis and therapeutic targets. The present review provides information on the biological and clinical significance of extracellular vesicles in tumors, especially in nasopharyngeal carcinoma.
\end{abstract}

\section{Contents}

1. Introduction

2. Exosomes and microvesicles

3. The roles of EVs in tumors

4. EVs in NPC

5. Contents of NPC-derived-EVs

6. Conclusion

Correspondence to: Professor Yiwen You or Dr Si Shi, Department of Otorhinolaryngology, Head and Neck Surgery, Affiliated Hospital of Nantong University, Nantong, Jiangsu 226001, P.R. China

E-mail: youyiwen_nantong@163.com

E-mail: shisient@163.com

${ }^{*}$ Contributed equally

Key words: extracellular vesicles, nasopharyngeal carcinoma, biomarker, HAX-1, MMP-13

\section{Introduction}

Intercellular communication is an essential hallmark of multicellular organisms. In recent years, the intercellular transfer of extracellular vesicles (EVs) have been discovered as a remarkable new system for cell-to-cell communication $(1,2)$. EVs are a heterogeneous group of membrane-enclosed vesicles ranging from 30 to $1,000 \mathrm{~nm}$ in size released by a variety of cells including cancer cells into the extracellular milieu (3). Then, they can diffuse to neighboring cells or be carried to distant locations where they may induce signal transduction or mediate the horizontal transfer of molecular information in recipient cells (4). Subsequent studies have shown that EVs reflect the biological function of parental cells by containing a variety of cargos such as proteins (including transmembrane and enclosing cytosolic proteins), lipids, messenger RNA (mRNA), microRNA (miRNA), non-coding RNAs and DNA (5). They can be detected in many human body fluids, including plasma (6), cerebrospinal fluid (7), urine (8), bronchoalveolar lavage (9), malignant ascites (10), saliva (11), semen (12), nasal lavage fluid and ascites (13).

The composition and function of EVs depend on their originating cells. Tumor-derived EVs have been recently discovered to be involved in the transfer of oncogenic cargo through which cancer cells can shape the tumor microenvironment and influence tumor progression and metastasis (14-17). Moreover, EVs derived from stromal cells in the tumor microenvironment may contribute to tumor progression through the transmission of their cargo to tumor cells $(18,19)$. This functional role of EVs in cancer development as well as their ability to be easily isolated from body fluids such as serum makes them an attractive candidate for biomarker development.

The present review will provide an overview of EVs in nasopharyngeal carcinoma (NPC), with a focus on their role in reprogramming tumor microenvironment and influencing tumor progression. The potential role of the molecules within EVs in NPC diagnosis and therapeutic targets will also be addressed.

\section{Exosomes and microvesicles}

Depending on the mode of release and the size, EVs are currently classified into two general types: exosomes and microvesicles 
(MVs) (20). They are distinct in biogenesis, morphology, molecular composition, size and buoyant density $(20,21)$. In the present review, we provide a brief description of exosomes and MVs prior to a discussion on their roles in NPC.

A population of EVs formed from the inward budding of intercellular endosomes result in multivesicular bodies (MVBs), which are known as exosomes. After inward budding, the MVBs fuse with the plasma membrane, releasing the exosomes into the extracellular space (22). Another release process involves the direct shedding by budding from the plasma membrane and this process forms MVs (23). In addition to the differences in the mode of release, the size of the vesicles is also used for characterization. Although different scales are used, MVs are from 100 to $1,000 \mathrm{~nm}$ and exosomes are smaller with a diameter of 30 to $100 \mathrm{~nm}$ (24). EVs are mostly isolated from body fluids and the supernatants of cultured cells by performing differential ultracentrifugation (24). Then, varied sized classes of EVs can be efficiently separated using their different floatation velocity (25). Currently, with the interest in their potential use in therapy or as biomarkers for disease, commercially available kits are being developed and marketed. Further characterization of isolated EVs requires immunoblotting, mass spectrometry and imaging techniques. In general, the specific EV marker proteins are typically used to show the purity and enrichment, besides, mass spectrometry approach is used to profile EV protein compositions. The morphology and size can be determined by electronic microscopy. The number and size distribution of EVs can be measured by nanoparticle tracking analysis, flow cytometry and tunable resistive pulse sensing (26). However, the distinctive features, properties and functional roles of each subtype are still under investigation.

\section{The roles of EVs in tumors}

EVs contain specific biologically active components that could be transferred from the original cell to the recipient cell to trigger downstream signaling events. They could directly influence the recipient cells via cell surface interactions or by manipulating the local and distant biological environment $(27,28)$. The above shows that EVs are implicated in a variety of tumor malignant biological properties including modulating tumor proliferation, invasion and metastasis, influencing angiogenesis, regulating immune response and conferring chemoresistance (29-32) (Fig. 1). Better understanding the duality roles of EVs in intercellular communication will help to gain further knowledge on the carcinogenic process.

EVsfacilitate tumor metastasis. Metastases refer to the concept that primary tumors infiltrate through the basement membrane and disseminate to the distant organs (33). Studies have reported that the ability for a tumor cell moving to metastatic colonization is not random (34). Tumor cells travelling through the microcirculation is multistage and complex, and more and more scientists have found that tumor microenvironment plays an essential role in this progression. Metastasis occurs when the tumor microenvironment is well suited and tumor cells degrade connective tissue, extracellular matrix and basement membrane components $(35,36)$. As this progression is via circulation, EVs also perform important roles in nearly all the steps. EVs might transfer the signals to other tumor cells and

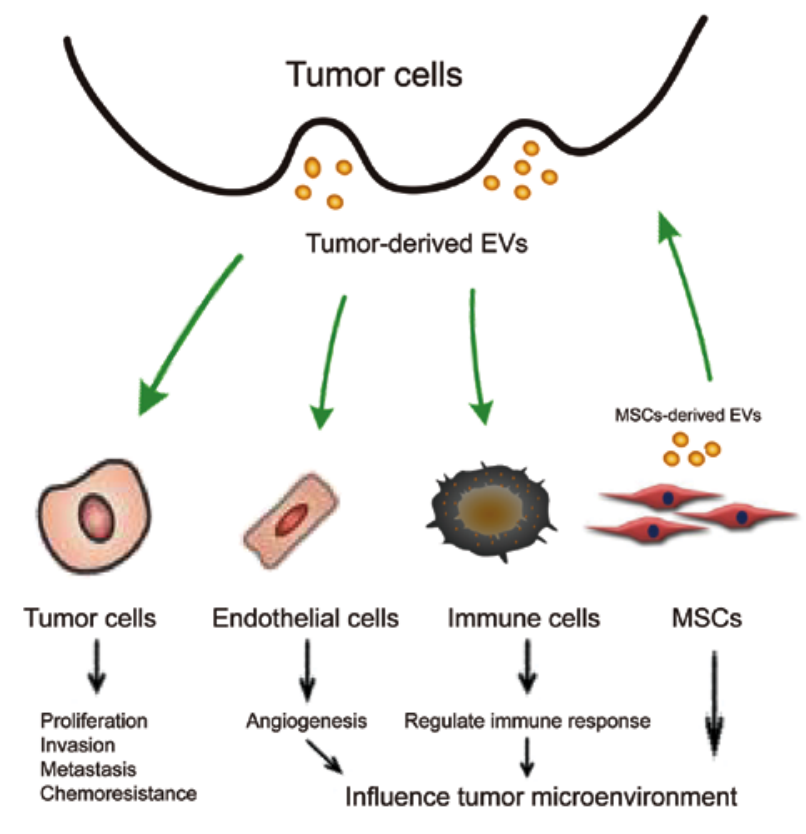

The roles of EVs in tumor

Figure 1. The roles of EVs in tumor. Tumor cell-derived EVs contain specific biologically active components and could transfer them to the recipient cell. They could be transferred to tumor cells, immune cells and endothelial cells to induce a variety of tumor malignant biological properties including tumor proliferation, invasion, metastasis, angiogenesis and regulate immune response and confer chemoresistance. MSCs in the tumor microenvironment could also secret EVs to influence tumor progression.

make EMT occur, which might help them to invade the distant tissues easily. Then, EVs might be uptaken by other cells to make the microenvironment more suitable for metastatic cells arrest. Besides, EVs might also regulate inflammation response pathways to help cell metastasis (15-19).

EVs facilitate tumor angiogenesis. Angiogenesis is the new blood vessel formation from pre-existing vasculature. It is a complex and multistep process consisting of proliferation, migration, invasion, adhesion and differentiation of endothelial cells (37). Angiogenesis occurs under various physiological and pathological conditions (38) and pathological angiogenesis could enhance tumor growth and metastasis by providing oxygen and nutrients (39). Intriguingly, previous studies have shown that genetic information can be transferred to human umbilical vein endothelial cells (HUVECs) to induce pathological angiogenesis (40). As EVs contain rich genetic information and can mediate exchange of molecules (41), studies have been performed to know the relationship between EVs and pathological angiogenesis.

EVs might be present in the fluids of the organism and several solid tissues (42). In recent years, there are many reports discussing the relationship between tumor-derived EVs with angiogenesis. According to the study of Kosaka, the EVs from tumor cells contain various pro-angiogenic molecules, such as bFGF, VEGF and TGF- $\beta$ (43). Futhermore, Kosaka et al (44) reported that EVs derived from metastatic tumor cells promoted angiogenesis through enhancing the tube formation and migration of endothelial cells in vitro. In addition, our previous study also detected that EVs from NPC cells 
are enriched of HAX-1, and could accelerate the proliferation and migration of HUVECs (45), collectively suggesting that EVs might be involved in the communication between tumor cells and HUVECs and play an important role in modulating angiogenesis.

EVs regulate tumor immunology. Immunoescape has been considered as one of the most common occurrences during tumor progression. Tumor cells might employ different methods to evade immune surveillance, accelerating their proliferation, migration and other biological malignant behavior. Increasing evidence shows that the dysregulation of immune system plays an essential role in tumor progression. As EVs can mediate cell-to-cell communication, they are also known to influence the immune system. EVs might contain receptors, proteins, RNA and DNA, which can be uptaken by immune cells and impact the immune microenvironment. This process could evoke immune responses, either make cells escape the immune response or activate immune suppression. Thus, investigating how tumor-derived EVs influence immune system might help us find the mechanism of tumorigenesis and develop new strategies for tumor therapy. Clayton et al (46) reported that EVs secreted by tumor cells might contribute to the production of extracellular adenosine and modulate $\mathrm{T}$ cells in the tumor environment. Wieckowsk et al (47) reported that tumor-derived EVs might be able to induce immune suppression by promoting $\mathrm{T}$ regulatory cell expansion and induce the apoptosis of CD8(+) T cells via activating the Fas/Fas ligand pathway. Tumor-derived EVs might also influence macrophages. EVs secreted by prostate cancer contained high level of MFG-E8 (milk fat globule-EGF factor 8 protein), when the macrophages were cocultured with the tumor cells, MFG-E8 expression was elevated and possibly polarized into M2 type tumor-associated macrophages. This type of cells could accelerate tumor progression (48). Besides, EVs might have impact on the complement system. Whitehead et al (49) showed that malignant cell-derived EVs could increase complement activation via calcium-sensitive pathways. Taken together, tumor derived EVs have important roles in the immune system.

EVs regulate drug sensitivity. By playing a role in facilitating cell to cell communication, EVs may mediate resistance to cytotoxic insults. In lung cancer, Xiao et al (50) found that EVs could regulate the sensitivity of tumor cells to cisplatin (DDP). They treated lung cancer cells A549 with DDP, and more EVs secreted in the supernatant were observed. Besides, in these EVs, the expression levels of some miRNAs and mRNAs associated with DDP sensitivity were dysregulated, transferring DDP resistance to those untreated cells. In breast cancer, drug-resistant breast cancer cells also released EVs to confer adriamycin resistance to sensitive ones by delivering specific miRNAs (51-53). In prostate cancer, Corcoran et al (54) treated the cells with EVs derived from sera of patients undergoing docetaxel treatment, and after the treatment, these cells also showed response to docetaxel. These results showed that EVs play an important role in drug resistance and might act as new therapeutic targets.

EVs as biomarkers in tumor diagnostics. An invasive biopsy of tumor is the golden standard for most tumors, which might be difficult for the early detection in some patients. As reported above, the physiological state of EVs depends on their originating cells and EVs could be detected in human body fluids, such as plasma, cerebrospinal fluid, saliva and urine. This makes them easily isolated and act as new disease biomarkers $(24,55,56)$. Tumor derived EVs contain specific proteins, mRNAs, miRNAs, which could reflect the states of tumor cells, more and more scientists are devoted to utilizing EVs for early diagnosis and assessment of therapeutic responses or prognosis of tumors (57). Studies show that specific proteins in EVs could be used for the early detection of tumors. Guan et al (58) reported that the expression level of MDA-9 and GRP78 were higher in EVs derived from metastatic melanoma patients than those without metastases. Thus, MDA-9 and GRP78 in EVs might be useful biomarkers for assessing the prognosis of melanoma. In plasma samples from ovarian cancer patients, EVs exhibited high expression of claudin-4, which might be used as biomarker for ovarian cancer detection (59). Besides proteins, miRNAs in EVs have also described as promising candidates as tumor biomarkers (60). Cazzoli et al (61) reported that miR-151a-5p, miR-30a-3p, miR-200b-5p, miR-629, miR-100 and miR-154-3p in EVs might be used to discriminate lung adenocarcinoma and granuloma. Madhavan et al (62) showed that miR-1246, miR-4644, miR-3976 and miR-4306 were upregulated in 83\% of pancreatic cancer derived EVs, but rarely in control groups and might act as highly sensitive biomarkers. Similar results were also found in prostate cancer, glioblastoma, and colon cancer (63-65). Not only EVs in serum could predict the diagnosis of tumor, EVs in other body fluid might also act as tumor biomarkers. Liu and colleagues (66) reported that miR-21 and miR-146a were upregulated in EVs derived from the cervicovaginal lavage specimens of cervical cancer patients. Therefore, EVs derived from body fluids might take messages of the original cells and provide a new biopsy technique for tumor diagnosis.

EVs as therapeutic targets in tumor treatments. Recently, scientists are devoted to use EVs as the therapeutic approach for tumor treatment. Hiltbrunner et al (67) reported that peptide-loaded EVs might be cancer treatment vehicles. They obtained ovalbumin-loaded dendritic cell-derived EVs from $\mathrm{MHCI}^{-/-}$mice, these EVs induce antigen-specific T cells response as wild-type EVs, EVs lacking MHC class I could add tumor infiltrating $\mathrm{T}$ cells and increase patients' overall survival. These results confirmed the prospective of using impersonalized EVs for tumors 68). More and more evidence focused on the application of EVs in tumor immunotherapy. Zhang et al (69) reported that EVs derived from interleukin (IL)-12 expressing renal cancer cells might express renal cell carcinoma-associated antigen G250 and GPI-IL-12, which could promote the proliferation of $\mathrm{T}$ cells and increase the immunogenicity and antitumor effects. This research is a novel way of EV-based vaccine for tumor treatments. Besides, EVs could be isolated from the stromal cells culturing media including MSCs, which might exert similar functions to those of MSCs. MSC-derived EVs could provide anticancer therapy via EV-mediated delivery of anticancer drugs (70). Lou et al (71) transfected adipose tissue-derived MSCs (AMSC) with miR-122, which made the effectively package of 
miR-122 into secreted EVs. After the communication between AMSCs and HCC cells, the proliferation of HCC cells was inhibited and the tumor cells were sensitive to the chemotherapeutic agents. This research represented a promising strategy for HCC chemotherapy. Shimbo et al (72) also reported that microRNA-143 containing MSCs could inhibit the migration of osteosarcoma cells.

\section{EVs in NPC}

NPC has a variety of incidence rates throughout the world, it is a squamous epithelial cancer arising from the nasopharynx with an incidence of 30-80/100,000 each year in China (73). The high mortality rate of this disease arises from the lack of effective early diagnosis, more importantly, most NPCs are poorly differentiated and have high tendency to metastasize and invade adjacent regions, more than one third of the patients will develop distant metastasis within 4 years (74). The prognosis may be very poor as soon as NPC patients have metastatic disease $(74,75)$. Thus, the identification of the mechanisms associated with NPC early diagnosis, metastasis and prognosis is of great significance. Various research has shown that EVs, which play important roles in tumor progression might also be present in NPC patient's serum and be recognized and taken up by other cells in the microenvironment. The intercellular communication between tumor cells and surrounding cells could facilitate tumor proliferation, metastasis and immune escape. Therefore, the functions of EVs in NPC progression and NPC-derived EVs might serve as biomarkers for early diagnosis and therapeutic targets.

EVs and NPC microenvironment. The notion of tumorassociated microenvironment refers to tumor-promoting and tumor-suppressing cells, soluble molecules and extracellular matrix components (76). It is obvious that tumor cells and stromal cells are in mutual dependence and in a sense, tumor microenvironment has become 'the end of the cancer cell' (77). In the tumor microenvironment, tumors release a variety of factors, which not only support tumor proliferation but also facilitate tumor cells to metastasize to distant organs (78). The factors include single cells, EVs and cytokines and they can influence distant tissues to have negative or positive feedback on themselves $(79,80)$. They might impact distant cell signaling and maintain a better environment for tumor progression.

Many studies have tried to understand the cellular interactions within the tumor microenvironment (81). As important components of tumor stromal cells, mesenchymal stem cells (MSCs) have received much attention in recent years (82). Studies have shown that MSCs could home to primary or metastatic tumor sites and contribute to the formation of the tumor microenvironment $(83,84)$. As paracrine effectors of MSCs, EVs have also been reported to play an important role during the interaction between tumor microenvironment and tumor cells, they could carry membrane and cytoplasmic components and mediate interactions with target cells (85). Previous studies have reported that EVs derived from MSCs might promote renal cancer cell growth and EVs from multiple myeloma (MM) patient bone marrow-derived MSCs promoted MM tumor growth $(18,86)$. A recent study reported that EVs also mediate the interaction between MSCs and NPC cells. The data showed that NPC cells could take up MSC-derived EVs and these EVs could promote tumor proliferation, migration and the process of epithelial-mesenchymal transition (EMT). Moreover, the study showed that FGF19 was highly expressed in MSC-EVs. Besides, MSC-EVs could stimulate NPC progression by activating the FGF19-FGFR4-dependent ERK signaling cascade and by modulating the EMT. These data indicated that EVs have an important role in NPC microenvironment and participate in influencing NPC progression (19).

Hypoxia-mediated release of EVs in the NPC environment. Recent clinical and preclinical findings in NPC suggest that tumor hypoxia which occurs in $>80 \%$ of NPC tumors playing a key role in NPC progression and resistance to therapy (87-89). Hypoxia, or oxygen deprivation, is one of the most common phenomena in human solid tumors. The lack of oxygen in the inner core of solid tumors, primarily due to increasing distance of tumor cells from blood vessels and the formation of aberrant blood vessels resulting in poor blood flow, is believed to contribute to tumor progression, as well as resistance to chemotherapy and radiotherapy $(90,91)$.

Cancer cells can adapt to a hypoxic microenvironment via multiple cellular mechanisms (92). EVs are among the most significant tumor promoting factors stimulated by hypoxia that influence adjacent tumor microenvironments (93). Hypoxia can remarkably stimulate EVs secretion; for instance, nucleic acids and proteins as transmission signals in EVs in the tumor microenvironment are involved in various functions, such as inducing intratumoral heterogeneity, altering immunological responses, producing cancer-associated fibroblasts and promoting angiogenesis and metastasis (92). Park et al (94)found that hypoxia $\left(1 \% \mathrm{O}_{2}\right)$ is insufficient to induce apoptosis; nevertheless, hypoxia can stimulate the release of EVs in human lung cancer cell line A549 and aid angiogenesis by chemo-tactically attracting endothelial cells and fibroblasts and by stimulating stromal cells to release angiogenesis-promoting cytokines. As in skin cancers, hypoxic A431 carcinoma cells released EVs enhancing angiogenesis in a chorioallantoic membrane assay and metastasis. Aga et al (95) demonstrated that endogenous hypoxia-inducible factor 1 alpha $(\mathrm{HIF} 1-\alpha)$ is detectable in EVs and that latent membrane protein 1 (LMP1) could increase the level of HIF1- $\alpha$ in EVs. The present study found that in NPC, hypoxia stimulated MMP-13 expression in EVs in a HIF-1 $\alpha$ dependent manner. Moreover, MMP-13 in EVs significantly upregulated vimentin expression, while decreasing E-cadherin level in NPC cells, in vitro and in vivo (96).

The immunoregulatory properties of EVs in NPC. Heavy lymphoid infiltration in the primary tumor sites is an important biologic feature of NPC (97). EVs, which act as intercellular vehicles are also reported as important mediators in NPC progression and immune escape. Ye et al (98) isolated EVs from the serum of NPC patients and found the concentration of EVs was positively correlated with lymph node stage and poor prognosis of NPC patients. To further confirm the high level of EVs in patients with lymph node metastasis was associated with T-cell immune response, the scientists treated T cells with EVs derived from the supernatant of NPC cells TW03. The results showed that TW03-derived EVs could inhibit the proliferation of T-cell and the differentiation of 
Th1 and Th17 and induce regulatory T cells (Treg cells) by altering p-ERK and p-STAT. Besides, NPC derived EVs also have anti-inflammatory effects and increase the expression of proinflammatory cytokines. These findings suggested that EVs might be potential targets for NPC immunotherapy. Some scientists also focused on Treg cells within the tumor site and investigated the mechanisms of Treg recruitment and the interaction between NPC-EVs and Treg cells. The results showed that CCL20 was highly expressed in NPC-EVs, which might play an important role in the recruitment of human Treg into tumor sites. Besides, NPC-EVs could induce the conversion of $\mathrm{CD} 4{ }^{+} \mathrm{CD} 25-\mathrm{T}$ cells into $\mathrm{CD} 4{ }^{+} \mathrm{CD} 25^{+}$Treg, then promote their regulatory phenotype and increase the suppressive function of Treg. The results confirmed that NPC-EVs in the tumor microenvironment could interact with Treg to exert immunoregulatory properties. In a word, NPC-EVs might be a newly defined way to regulate the immune system of NPC (99).

\section{Contents of NPC-derived-EVs}

EVs are reported to contain a variety of mRNAs, miRNAs and proteins, which play an essential role in tumor malignant behavior. NPC derived EVs also interact with other cells and are involved in NPC proliferation, invasion and metastasis. Thus, the studies highlight the important roles of EVs as they might contribute to NPC progression. Abundant research has been carried out to characterize the content of EVs.

HAX-1 in NPC-derived-EVs. HS1-associated protein X-1 (HAX-1) was identied more than 10 years ago as a novel protein with ubiquitous tissue expression (100). It has been shown that HAX-1 interacts with the 3'-untranslated regions (3'UTR) of a variety of proteins and binds to the 3 -untranslated regions of certain mRNAs involvement in multiple signaling pathways and cellular processes (101106). HAX-1 is reported to be associated with biological processes such as cell apoptosis, cell motility and endocytosis, so it also plays an important role in regulating tumor cell apoptosis, proliferation and invasion. HAX-1 expression is a predictor of tumorigenesis, growth, progression, invasion, and metastasis of many human malignancies $(107,108)$, and is overexpressed in many tumors $(107,109,110)$ such as esophageal squamous cell carcinoma $(111,112)$, colorectal cancer (113), oral squamous cell carcinoma, lung cancer, lymphoma, melanoma (114), leukemia, myeloma, breast cancer and hepatoma (115). In our previous study, we also found that HAX-1 was highly expressed in NPC tissues compared with normal tissues. Besides, its expression level was correlated with lymph node metastasis and clinical stage of NPC patients, it could also predict poor prognosis (45). As reported, tumor-derived EVs play an important role in tumor progression and metastasis by acting as intercellular communicators $(116,117)$. The roles of NPC-derived EVs in NPC tumor growth, migration and angiogenesis were also confirmed in our previous study (45). Moreover, we found surprisingly that HAX-1 was selectively packaged in NPC-derived EVs. It is highly expressed in EVs derived from NPC patients compared with healthy donors (45). To confirm the role of EVs regulated by HAX-1, we stimulated HUVECs with EVs which contain different levels of HAX-1 protein. As expected, HAX-1-containing EVs could accelerate HUVECs proliferation, migration and angiogenesis. Moreover, the intracellular downstream pathways were also activated during the interaction between recipient HUVECs with HAX-1-containing EVs. So the expression level of HAX-1 in NPC patients derived EVs might be a biomarker for NPC diagnosis and act as a therapy target (45).

$M M P 13$ in NPC-derived-EVs. MMPs are members of the metzincin superfamily which comprises zinc- and calciumdependent enzymes comprising more than 24 subtypes (118). It is widely accepted that MMPs mediate degradation and modify most components of the extracellular matrix (ECM) and the basal membrane (BM), which is critical for cancer invasion and metastasis (119-121). As one of the most important MMP genes, the MMP-13 gene, also known as collagenase-3, is located in chromosome 11q22, spanning approximately $12.5 \mathrm{~kb}$ and consists of ten exons and nine introns (122). MMP-13 has the ability to disrupt collagen types I, II, III, IV, VI and X (123). Previous studies have supported that MMP-13 is found to have high expression in various types of tumors, including those from different parts of an individual's body, such as the breast, stomach, head, neck, larynx and colorectum (124). In this sense, upregulation of MMP-13 expression has been associated with increases in invasion and metastasis, and MMP-13 may have a potential influence on risks of cancer development and progression $(125,126)$. Previous evidence showed that MMP-13 acts as a potential intermediate between low expression of microRNA-125b and increasing metastatic potential of nonsmall cell lung cancer (118). Fan et al (127) found that leptin signaling enhances cell invasion and promotes the metastasis of human pancreatic cancer via increasing MMP-13 production. Sedighi et al (123) found that MMP-13 level was an accurate diagnostic marker especially to differentiate pre-invasive/invasive lesions from normal controls (sensitivity and specificity: $100 \%$ ). These findings indicate a potential clinical significance of serum MMP-13 measurement for early detection and prognostic assessment in ESCC patients. In the present study, we first demonstrated that MMP-13 was overexpressed in NPC cells and EVs purified from conditioned medium (CM) as well as NPC patient plasma. Furthermore, MMP-13-containing EVs facilitated the metastasis of NPC cells as well as angiogenesis which provided novel insight into the vital role of MMP-13containing EVs in NPC progression which might offer unique insights for potential therapeutic strategies for NPC progressions. Then, we further investigated that NPC cells exposed to hypoxia release EVs containing higher level of MMP-13 in HIF-1 $\alpha$ dependency that enhances metastases by inducing EMT in vitro and in vivo. We further found overexpression of HIF-1 $\alpha$ and MMP-13 might be involved in the carcinogenesis and development of NPC and they were associated with poor patient prognosis. Thus, MMP-13 overexpression was triggered by hypoxia/HIF-1 $\alpha$ as an important mechanism that induced EMT and tumor invasion in NPC (96).

\section{Conclusion}

Current studies suggest that EVs are important regulators of cell-cell communication. The growing knowledge on their roles in urologic malignancies provides the basis for novel 
therapeutic strategies. In addition, nucleic acid and the protein content of EVs hold promise for tumor therapy. For NPC, more and more studies have showed the importance of EVs in tumor proliferation, metastasis, angiogenesis, immune regulation and so on. Besides, EVs could act as potential biomarkers in the early diagnosis of NPC and be used in NPC treatments. However, there are still many questions to be answered including its deeper mechanisms. So further fundamental researches and pre-clinical trials need to be carried out to help better understanding of the role of EVs in NPC. We hope the future studies will give evidence for the large-scale clinical utilization of EVs.

\section{Acknowledgements}

The present study was supported by grants from the National Natural Science Foundation of China (grant nos. 81672682, 81602385 and 81702707), the Major Scientific Research Project of Jiangsu province (grant no. BE2017680), the Natural Science Foundation of Jiangsu Province (grant no. BK20151266), the Nantong Application Research Project (grant nos. MS32015020 and HS2016001), the Innovative Research Project for postgraduate students of Jiangsu province (no. SJLX15_0645 to L.B.).

\section{References}

1. Frühbeis C, Fröhlich D and Krämer-Albers EM: Emerging roles of exosomes in neuron-glia communication. Front Physiol 3: 119, 2012.

2. Frühbeis C, Fröhlich D, Kuo WP, Amphornrat J, Thilemann S, Saab AS, Kirchhoff F, Möbius W, Goebbels S, Nave KA, et al: Neurotransmitter-triggered transfer of exosomes mediates oligodendrocyte-neuron communication. PLoS Biol 11: e1001604, 2013

3. Abels ER and Breakefield XO: Introduction to extracellular vesicles: Biogenesis, RNA cargo selection, content, release, and uptake. Cell Mol Neurobiol 36: 301-312, 2016.

4. Syn N, Wang L, Sethi G, Thiery JP and Goh BC: Exosomemediated metastasis: From epithelial-mesenchymal transition to escape from immunosurveillance. Trends Pharmacol Sci 37: 606-617, 2016

5. Zaborowski MP, Balaj L, Breakefield XO and Lai CP: Extracellular vesicles: Composition, biological relevance, and methods of study. Bioscience 65: 783-797, 2015.

6. Grant R, Ansa-Addo E, Stratton D, Antwi-Baffour S, Jorfi S, Kholia S, Krige L, Lange S and Inal J: A filtration-based protocol to isolate human plasma membrane-derived vesicles and exosomes from blood plasma. J Immunol Methods 371: 143-151, 2011.

7. Street JM, Barran PE, Mackay CL, Weidt S, Balmforth C, Walsh TS, Chalmers RT, Webb DJ and Dear JW: Identification and proteomic profiling of exosomes in human cerebrospinal fluid. J Transl Med 10: 5, 2012.

8. Pisitkun T, Shen RF and Knepper MA: Identification and proteomic profiling of exosomes in human urine. Proc Natl Acad Sci USA 101: 13368-13373, 2004.

9. Prado N, Marazuela EG, Segura E, Fernández-García H, Villalba M, Théry C, Rodríguez R and Batanero E: Exosomes from bronchoalveolar fluid of tolerized mice prevent allergic reaction. J Immunol 181: 1519-1525, 2008.

10. Runz S, Keller S, Rupp C, Stoeck A, Issa Y, Koensgen D, Mustea A, Sehouli J, Kristiansen G and Altevogt P: Malignant ascites-derived exosomes of ovarian carcinoma patients contain CD24 and EpCAM. Gynecol Oncol 107: 563-571, 2007.

11. Ogawa Y, Miura Y, Harazono A, Kanai-Azuma M, Akimoto Y, Kawakami H, Yamaguchi T, Toda T, Endo T, Tsubuki M, et al: Proteomic analysis of two types of exosomes in human whole saliva. Biol Pharm Bull 34: 13-23, 2011.

12. Aalberts M, van Dissel-Emiliani FM, van Adrichem NP, van Wijnen M, Wauben MH, Stout TA and Stoorvogel W: Identification of distinct populations of prostasomes that differentially express prostate stem cell antigen, annexin A1, and GLIPR2 in humans. Biol Reprod 86: 82, 2012.
13. Andre F, Schartz NE, Movassagh M, Flament C, Pautier P, Morice P, Pomel C, Lhomme C, Escudier B, Le Chevalier T, et al: Malignant effusions and immunogenic tumour-derived exosomes. Lancet 360: 295-305, 2002.

14. Rak J and Guha A: Extracellular vesicles - vehicles that spread cancer genes. BioEssays 34: 489-497, 2012.

15. Khan S, Jutzy JM, Aspe JR, McGregor DW, Neidigh JW and Wall NR: Survivin is released from cancer cells via exosomes. Apoptosis 16: 1-12, 2011.

16. Dutta S, Warshall C, Bandyopadhyay C, Dutta D and Chandran B: Interactions between exosomes from breast cancer cells and primary mammary epithelial cells leads to generation of reactive oxygen species which induce DNA damage response, stabilization of p53 and autophagy in epithelial cells. PLoS One 9: e97580, 2014.

17. Hoshino A, Costa-Silva B, Shen TL, Rodrigues G, Hashimoto A, Tesic Mark M, Molina H, Kohsaka S, Di Giannatale A, Ceder S, et al: Tumour exosome integrins determine organotropic metastasis. Nature 527: 329-335, 2015.

18. Roccaro AM, Sacco A, Maiso P, Azab AK, Tai YT, Reagan M, Azab F, Flores LM, Campigotto F, Weller E, et al: BM mesenchymal stromal cell-derived exosomes facilitate multiple myeloma progression. J Clin Invest 123: 1542-1555, 2013.

19. Shi S, Zhang Q, Xia Y, You B, Shan Y, Bao L, Li L, You Y and $\mathrm{Gu} \mathrm{Z}$ : Mesenchymal stem cell-derived exosomes facilitate nasopharyngeal carcinoma progression. Am J Cancer Res 6: 459-472, 2016.

20. Colombo M, Raposo G and Théry C: Biogenesis, secretion, and intercellular interactions of exosomes and other extracellular vesicles. Annu Rev Cell Dev Biol 30: 255-289, 2014.

21. Tkach $\mathrm{M}$ and Théry $\mathrm{C}$ : Communication by extracellular vesicles: Where we are and where we need to go. Cell 164: 1226-1232, 2016.

22. Mathivanan S, Ji H and Simpson RJ: Exosomes: Extracellular organelles important in intercellular communication. J Proteomics 73: 1907-1920, 2010.

23. Martins VR, Dias MS and Hainaut P: Tumor-cell-derived microvesicles as carriers of molecular information in cancer. Curr Opin Oncol 25: 66-75, 2013.

24. Raposo G and Stoorvogel W: Extracellular vesicles: Exosomes, microvesicles, and friends. J Cell Biol 200: 373-383, 2013.

25. Taylor DD, Zacharias W and Gercel-Taylor C: Exosome isolation for proteomic analyses and RNA profiling. Methods Mol Biol 728: 235-246, 2011.

26. Momen-Heravi F, Balaj L, Alian S, Tigges J, Toxavidis V, Ericsson M, Distel RJ, Ivanov AR, Skog J and Kuo WP: Alternative methods for characterization of extracellular vesicles. Front Physiol 3: 354, 2012.

27. Al-Nedawi K, Meehan B and Rak J: Microvesicles: Messengers and mediators of tumor progression. Cell Cycle 8: 2014-2018, 2009.

28. Ratajczak J, Wysoczynski M, Hayek F, Janowska-Wieczorek A and Ratajczak MZ: Membrane-derived microvesicles: Important and underappreciated mediators of cell-to-cell communication. Leukemia 20: 1487-1495, 2006

29. Azmi AS, Bao B and Sarkar FH: Exosomes in cancer development, metastasis, and drug resistance: A comprehensive review. Cancer Metastasis Rev 32: 623-642, 2013.

30. Yu DD, Wu Y, Shen HY, Lv MM, Chen WX, Zhang XH, Zhong SL, Tang JH and Zhao JH: Exosomes in development, metastasis and drug resistance of breast cancer. Cancer Sci 106: 959-964, 2015

31. Robinson SM, Fan L, White SA, Charnley RM and Mann J: The role of exosomes in the pathogenesis of pancreatic ductal adenocarcinoma. Int J Biochem Cell Biol 75: 131-139, 2016.

32. Kahlert $C$ and Kalluri R: Exosomes in tumor microenvironment influence cancer progression and metastasis. J Mol Med (Berl) 91: 431-437, 2013.

33. Thiery JP, Acloque H, Huang RY and Nieto MA: Epithelialmesenchymal transitions in development and disease. Cell 139: 871-890, 2009.

34. Paget S: The distribution of secondary growths in cancer of the breast. 1889. Cancer Metastasis Rev 8: 98-101, 1989.

35. Funasaka T and Raz A: The role of autocrine motility factor in tumor and tumor microenvironment. Cancer Metastasis Rev 26: 725-735, 2007.

36. Funasaka $\mathrm{T}$ and Wong RW: The role of nuclear pore complex in tumor microenvironment and metastasis. Cancer Metastasis Rev 30: 239-251, 2011.

37. Carmeliet $\mathrm{P}$ and Jain RK: Angiogenesis in cancer and other diseases. Nature 407: 249-257, 2000. 
38. Yoon YJ, Kim DK, Yoon CM, Park J, Kim YK, Roh TY and Gho YS: Egr-1 activation by cancer-derived extracellular vesicles promotes endothelial cell migration via ERK1/2 and JNK signaling pathways. PLoS One 9: e115170, 2014.

39. Folkman J: Tumor angiogenesis: Therapeutic implications. $\mathrm{N}$ Engl J Med 285: 1182-1186, 1971.

40. Liu Y, Luo F, Wang B, Li H, Xu Y, Liu X, Shi L, Lu X, Xu W, Lu L, et al: STAT3-regulated exosomal miR-21 promotes angiogenesis and is involved in neoplastic processes of transformed human bronchial epithelial cells. Cancer Lett 370: 125-135, 2016

41. Zomer A, Maynard C, Verweij FJ, Kamermans A, Schäfer R, Beerling E, Schiffelers RM, de Wit E, Berenguer J, Ellenbroek SIJ, et al: In Vivo imaging reveals extracellular vesicle-mediated phenocopying of metastatic behavior. Cell 161: 1046-1057, 2015.

42. Fleury A, Martinez MC and Le Lay S: Extracellular vesicles as therapeutic tools in cardiovascular diseases. Front Immunol 5 : 370, 2014.

43. Kosaka N: Decoding the secret of cancer by means of extracellular vesicles. J Clin Med 5: 5, 2016.

44. Kosaka N, Iguchi H, Hagiwara K, Yoshioka Y, Takeshita F and Ochiya T: Neutral sphingomyelinase 2 (nSMase2)-dependent exosomal transfer of angiogenic microRNAs regulate cancer cell metastasis. J Biol Chem 288: 10849-10859, 2013.

45. You B, Cao X, Shao X, Ni H, Shi S, Shan Y, Gu Z and You Y: Clinical and biological significance of HAX-1 overexpression in nasopharyngeal carcinoma. Oncotarget 7: 12505-12524, 2016.

46. Clayton A, Al-Taei S, Webber J, Mason MD and Tabi Z: Cancer exosomes express CD39 and CD73, which suppress T cells through adenosine production. J Immunol 187: 676-683, 2011.

47. Wieckowski EU, Visus C, Szajnik M, Szczepanski MJ, Storkus WJ and Whiteside TL: Tumor-derived microvesicles promote regulatory $\mathrm{T}$ cell expansion and induce apoptosis in tumor-reactive activated CD8 ${ }^{+} \mathrm{T}$ lymphocytes. J Immunol 183 : 3720-3730, 2009.

48. Soki FN, Koh AJ, Jones JD, Kim YW, Dai J, Keller ET, Pienta KJ Atabai K, Roca H and McCauley LK: Polarization of prostate cancer-associated macrophages is induced by milk fat globuleEGF factor 8 (MFG-E8)-mediated efferocytosis. J Biol Chem 289: 24560-24572, 2014

49. Whitehead B, Wu L, Hvam ML, Aslan H, Dong M, Dyrskjøt L, Ostenfeld MS, Moghimi SM and Howard KA: Tumour exosomes display differential mechanical and complement activation properties dependent on malignant state: Implications in endothelial leakiness. J Extracell Vesicles 4: 29685, 2015.

50. Xiao X, Yu S, Li S, Wu J, Ma R, Cao H, Zhu Y and Feng J: Exosomes: Decreased sensitivity of lung cancer A549 cells to cisplatin. PLoS One 9: e89534, 2014.

51. Chen WX, Liu XM, Lv MM, Chen L, Zhao JH, Zhong SL, Ji MH, $\mathrm{Hu} \mathrm{Q}$, Luo Z, Wu JZ, et al: Exosomes from drug-resistant breast cancer cells transmit chemoresistance by a horizontal transfer of microRNAs. PLoS One 9: e95240, 2014.

52. Zhong S, Chen X, Wang D, Zhang X, Shen H, Yang S, Lv M, Tang J and Zhao J: MicroRNA expression profiles of drugresistance breast cancer cells and their exosomes. Oncotarget 7 : 19601-19609, 2016.

53. Yu DD, Wu Y, Zhang XH, Lv MM, Chen WX, Chen X, Yang SJ, Shen H, Zhong SL, Tang JH, et al: Exosomes from adriamycinresistant breast cancer cells transmit drug resistance partly by delivering miR-222. Tumour Biol 37: 3227-3235, 2016.

54. Corcoran C, Rani S, O'Brien K, O'Neill A, Prencipe M, Sheikh R, Webb G, McDermott R, Watson W, Crown J, et al: Docetaxelresistance in prostate cancer: Evaluating associated phenotypic changes and potential for resistance transfer via exosomes. PLoS One 7: e50999, 2012.

55. Brinton LT, Sloane HS, Kester M and Kelly KA: Formation and role of exosomes in cancer. Cell Mol Life Sci 72: 659-671, 2015.

56. Yáñez-Mó M, Siljander PR, Andreu Z, Zavec AB, Borràs FE Buzas EI, Buzas K, Casal E, Cappello F, Carvalho J, et al: Biological properties of extracellular vesicles and their physiological functions. J Extracell Vesicles 4: 27066, 2015.

57. Silva M and Melo SA: Non-coding RNAs in exosomes: New players in cancer biology. Curr Genomics 16: 295-303, 2015.

58. Guan M, Chen X, Ma Y, Tang L, Guan L, Ren X, Yu B, Zhang W and Su B: MDA-9 and GRP78 as potential diagnostic biomarkers for early detection of melanoma metastasis. Tumour Biol 36 : 2973-2982, 2015.

59. Li J, Sherman-Baust CA, Tsai-Turton M, Bristow RE, Roden RB and Morin PJ: Claudin-containing exosomes in the peripheral circulation of women with ovarian cancer. BMC Cancer 9: 244, 2009.
60. Fujita Y, Kuwano K, Ochiya T and Takeshita F: The impact of extracellular vesicle-encapsulated circulating microRNAs in lung cancer research. BioMed Res Int 2014: 486413, 2014.

61. Cazzoli R, Buttitta F, Di Nicola M, Malatesta S, Marchetti A, Rom WN and Pass HI: microRNAs derived from circulating exosomes as noninvasive biomarkers for screening and diagnosing lung cancer. J Thorac Oncol 8: 1156-1162, 2013.

62. Madhavan B, Yue S, Galli U, Rana S, Gross W, Müller M, Giese NA, Kalthoff H, Becker T, Büchler MW, et al: Combined evaluation of a panel of protein and miRNA serum-exosome biomarkers for pancreatic cancer diagnosis increases sensitivity and specificity. Int J Cancer 136: 2616-2627, 2015.

63. Bryant RJ, Pawlowski T, Catto JW, Marsden G, Vessella RL, Rhees B, Kuslich C, Visakorpi T and Hamdy FC: Changes in circulating microRNA levels associated with prostate cancer. $\mathrm{Br}$ J Cancer 106: 768-774, 2012.

64. Manterola L, Guruceaga E, Gállego Pérez-Larraya J, GonzálezHuarriz M, Jauregui P, Tejada S, Diez-Valle R, Segura V, Samprón N, Barrena C, et al: A small noncoding RNA signature found in exosomes of GBM patient serum as a diagnostic tool. Neuro Oncol 16: 520-527, 2014.

65. Ogata-Kawata H, Izumiya M, Kurioka D, Honma Y, Yamada Y, Furuta K, Gunji T, Ohta H, Okamoto H, Sonoda $\mathrm{H}$, et al: Circulating exosomal microRNAs as biomarkers of colon cancer. PLoS One 9: e92921, 2014.

66. Liu J, Sun H, Wang X, Yu Q, Li S, Yu X and Gong W: Increased exosomal microRNA-21 and microRNA-146a levels in the cervicovaginal lavage specimens of patients with cervical cancer. Int J Mol Sci 15: 758-773, 2014.

67. Hiltbrunner S, Larssen P, Eldh M, Martinez-Bravo MJ, Wagner AK, Karlsson MC and Gabrielsson S: Exosomal cancer immunotherapy is independent of MHC molecules on exosomes. Oncotarget 7: 38707-38717, 2016.

68. Rafi MA and Omidi Y: A prospective highlight on exosomal nanoshuttles and cancer immunotherapy and vaccination. Bioimpacts 5: 117-122, 2015.

69. Zhang Y, Luo CL, He BC, Zhang JM, Cheng G and Wu XH: Exosomes derived from IL-12-anchored renal cancer cells increase induction of specific antitumor response in vitro: A novel vaccine for renal cell carcinoma. Int J Oncol 36: 133-140, 2010.

70. Pashoutan Sarvar D, Shamsasenjan K and Akbarzadehlaleh P: Mesenchymal stem cell-derived exosomes: New opportunity in cell-free therapy. Adv Pharm Bull 6: 293-299, 2016.

71. Lou G, Song X, Yang F, Wu S, Wang J, Chen Z and Liu Y: Exosomes derived from miR-122-modified adipose tissuederived MSCs increase chemosensitivity of hepatocellular carcinoma. J Hematol Oncol 8: 122, 2015.

72. Shimbo K, Miyaki S, Ishitobi H, Kato Y, Kubo T, Shimose S and Ochi M: Exosome-formed synthetic microRNA-143 is transferred to osteosarcoma cells and inhibits their migration. Biochem Biophys Res Commun 445: 381-387, 2014.

73. Brennan B: Nasopharyngeal carcinoma. Orphanet J Rare Dis 1 23, 2006.

74. Lee AW, Yau TK, Wong DH, Chan EW, Yeung RM, Ng WT, Tong M, Soong IS and Sze WM: Treatment of stage IV(A-B) nasopharyngeal carcinoma by induction-concurrent chemoradiotherapy and accelerated fractionation. Int J Radiat Oncol Biol Phys 63: 1331-1338, 2005.

75. Strazzulla A, Barreca GS, Giancotti A, Pisani V, Costa C, Zicca E, La Boria A, Roveda L, Liberto MC, Tucci L, et al: Nasopharyngeal carcinoma: Review of the literature with a focus on therapeutical implications. Infez Med 23: 224-229, 2015.

76. Hanahan D and Weinberg RA: Hallmarks of cancer: The next generation. Cell 144: 646-674, 2011.

77. Sonnenschein $\mathrm{C}$ and Soto AM: The death of the cancer cell. Cancer Res 71: 4334-4337, 2011.

78. Robinson BD, Sica GL, Liu YF, Rohan TE, Gertler FB, Condeelis JS and Jones JG: Tumor microenvironment of metastasis in human breast carcinoma: A potential prognostic marker linked to hematogenous dissemination. Clin Cancer Res 15: 2433-2441, 2009.

79. Redon CE, Dickey JS, Nakamura AJ, Kareva IG, Naf D, Nowsheen S, Kryston TB, Bonner WM, Georgakilas AG and Sedelnikova OA: Tumors induce complex DNA damage in distant proliferative tissues in vivo. Proc Natl Acad Sci USA 107: 17992-17997, 2010

80. Critchley-Thorne RJ, Simons DL, Yan N, Miyahira AK, Dirbas FM, Johnson DL, Swetter SM, Carlson RW, Fisher GA, Koong A, et al: Impaired interferon signaling is a common immune defect in human cancer. Proc Natl Acad Sci USA 106: 9010-9015, 2009 
81. Gourzones C, Barjon C and Busson P: Host-tumor interactions in nasopharyngeal carcinomas. Semin Cancer Biol 22: 127-136, 2012.

82. Salem HK and Thiemermann C: Mesenchymal stromal cells: Current understanding and clinical status. Stem Cells 28 585-596, 2010.

83. Droujinine IA, Eckert MA and Zhao W: To grab the stroma by the horns: From biology to cancer therapy with mesenchymal stem cells. Oncotarget 4: 651-664, 2013.

84.Kidd S, Spaeth E, Dembinski JL, Dietrich M, Watson K, Klopp A, Battula VL, Weil M, Andreeff M and Marini FC: Direct evidence of mesenchymal stem cell tropism for tumor and wounding microenvironments using in vivo bioluminescent imaging. Stem Cells 27: 2614-2623, 2009.

85. Vlassov AV, Magdaleno S, Setterquist R and Conrad R: Exosomes: Current knowledge of their composition, biological functions, and diagnostic and therapeutic potentials. Biochim Biophys Acta 1820: 940-948, 2012.

86. Du T, Ju G, Wu S, Cheng Z, Cheng J, Zou X, Zhang G, Miao S, Liu G and Zhu Y: Microvesicles derived from human Wharton's jelly mesenchymal stem cells promote human renal cancer cell growth and aggressiveness through induction of hepatocyte growth factor. PLoS One 9: e96836, 2014.

87. Yeh SH, Liu RS, Wu LC, Yang DJ, Yen SH, Chang CW, Yu TW, Chou KL and Chen KY: Fluorine-18 fluoromisonidazole tumour to muscle retention ratio for the detection of hypoxia in nasopharyngeal carcinoma. Eur J Nucl Med 23: 1378-1383, 1996.

88. Zheng YJ, Fan W, Zhao C, Yang XC, Cui NJ and Chen FJ: Clinical application of $99 \mathrm{mTc}-\mathrm{HL} 91$ hypoxia imaging in nasopharyngeal carcinoma. Ai Zheng 25: 378-381, 2006 (In Chinese).

89. Zheng YJ, Zhao C, Fan W, Liu H, Cui NJ and Chen FJ: Changes of hypoxia in primary lesion of nasopharyngeal carcinoma during the treatment course and the clinical value thereof Zhonghua Yi Xue Za Zhi 87: 2698-2702, 2007 (In Chinese)

90. Hong B, Lui VWY, Hashiguchi M, Hui EP and Chan ATC: Targeting tumor hypoxia in nasopharyngeal carcinoma. Head Neck 35: 133-145, 2013.

91. Janssen HL, Haustermans KM, Balm AJ and Begg AC: Hypoxia in head and neck cancer: How much, how important? Head Neck 27: 622-638, 2005

92. Yang Y, Yang X, Yang Y, Zhu H, Chen X, Zhang H, Wang F, Qin $\mathrm{Q}$, Cheng $\mathrm{H}$ and Sun $\mathrm{X}$ : Exosomes: A promising factor involved in cancer hypoxic microenvironments. Curr Med Chem 22: 4189-4195, 2015.

93. Yang X, Zhu H, Ge Y, Liu J, Cai J, Qin Q, Zhan L, Zhang C, $\mathrm{Xu} \mathrm{L}$, Liu Z, et al: Melittin enhances radiosensitivity of hypoxic head and neck squamous cell carcinoma by suppressing HIF-1 $\alpha$. Tumour Biol 35: 10443-10448, 2014.

94. Park JE, Tan HS, Datta A, Lai RC, Zhang H, Meng W, Lim SK and Sze SK: Hypoxic tumor cell modulates its microenvironment to enhance angiogenic and metastatic potential by secretion of proteins and exosomes. Mol Cell Proteomics 9: 1085-1099, 2010

95. Aga M, Bentz GL, Raffa S, Torrisi MR, Kondo S, Wakisaka N, Yoshizaki T, Pagano JS and Shackelford J: Exosomal HIF1d supports invasive potential of nasopharyngeal carcinomaassociated LMP1-positive exosomes. Oncogene 33: 4613-4622, 2014

96. You Y, Shan Y, Chen J, Yue H, You B, Shi S, Li X and Cao X: Matrix metalloproteinase 13-containing exosomes promote nasopharyngeal carcinoma metastasis. Cancer Sci 106 1669-1677, 2015.

97. Ferradini L, Miescher S, Stoeck M, Busson P, Barras C, CerfBensussan N, Lipinski M, von Fliedner V and Tursz T: Cytotoxic potential despite impaired activation pathways in T lymphocytes infiltrating nasopharyngeal carcinoma. Int J Cancer 47: 362-370, 1991

98. Ye SB, Li ZL, Luo DH, Huang BJ, Chen YS, Zhang XS, Cui J, Zeng YX and Li J: Tumor-derived exosomes promote tumor progression and T-cell dysfunction through the regulation of enriched exosomal microRNAs in human nasopharyngeal carcinoma. Oncotarget 5: 5439-5452, 2014.

99. Mrizak D, Martin N, Barjon C, Jimenez-Pailhes AS, Mustapha R, Niki T, Guigay J, Pancré V, de Launoit Y, Busson P, et al: Effect of nasopharyngeal carcinoma-derived exosomes on human regulatory T cells. J Natl Cancer Inst 107: 363, 2014.

100. Simmen T: Hax-1: A regulator of calcium signaling and apoptosis progression with multiple roles in human disease. Expert Opin Ther Targets 15: 741-751, 2011.
101. Fadeel B and Grzybowska E: HAX-1: A multifunctional protein with emerging roles in human disease. Biochim Biophys Acta 1790: 1139-1148, 2009.

102. Sharp TV, Wang HW, Koumi A, Hollyman D, Endo Y, Ye H, Du MQ and Boshoff C: K15 protein of Kaposi's sarcoma-associated herpesvirus is latently expressed and binds to HAX-1, a protein with antiapoptotic function. J Virol 76: 802-816, 2002.

103. Lee AY, Lee Y, Park YK, Bae KH, Cho S, Lee DH, Park BC, Kang S and Park SG: HS 1-associated protein X-1 is cleaved by caspase-3 during apoptosis. Mol Cells 25: 86-90, 2008

104. Vafiadaki E, Arvanitis DA, Pagakis SN, Papalouka V, Sanoudou D, Kontrogianni-Konstantopoulos A and Kranias EG: The anti-apoptotic protein HAX-1 interacts with SERCA2 and regulates its protein levels to promote cell survival. Mol Biol Cell 20: 306-318, 2009.

105. Al-Maghrebi M, Brulé H, Padkina M, Allen C, Holmes WM and Zehner ZE: The 3' untranslated region of human vimentin mRNA interacts with protein complexes containing eEF-1 gamma and HAX-1. Nucleic Acids Res 30: 5017-5028, 2002.

106. Sarnowska E, Grzybowska EA, Sobczak K, Konopinski R, Wilczynska A, Szwarc M, Sarnowski TJ, Krzyzosiak WJ and Siedlecki JA: Hairpin structure within the 3'UTR of DNA polymerase beta mRNA acts as a post-transcriptional regulatory element and interacts with Hax-1. Nucleic Acids Res 35: 5499-5510, 2007.

107. Ramsay AG, Keppler MD, Jazayeri M, Thomas GJ, Parsons M, Violette S, Weinreb P, Hart IR and Marshall JF: HS1-associated protein $\mathrm{X}-1$ regulates carcinoma cell migration and invasion via clathrin-mediated endocytosis of integrin alphavbeta6. Cancer Res 67: 5275-5284, 2007.

108. Radhika V, Onesime D, Ha JH and Dhanasekaran N: Galpha13 stimulates cell migration through cortactin-interacting protein Hax-1. J Biol Chem 279: 49406-49413, 2004

109. Rhodes DR, Yu J, Shanker K, Deshpande N, Varambally R, Ghosh D, Barrette T, Pandey A and Chinnaiyan AM: ONCOMINE: A cancer microarray database and integrated data-mining platform. Neoplasia 6: 1-6, 2004.

110. Jiang Y,Zhang W, Kondo K, Klco JM, St Martin TB, Dufault MR, Madden SL, Kaelin WG Jr and Nacht M: Gene expression profiling in a renal cell carcinoma cell line: Dissecting VHL and hypoxia-dependent pathways. Mol Cancer Res 1: 453-462, 2003.

111. Li M, Tang Y, Zang W, Xuan X, Wang N, Ma Y, Wang Y, Dong Z and Zhao G: Analysis of HAX-1 gene expression in esophageal squamous cell carcinoma. Diagn Pathol 8: 47, 2013.

112. Sun SJ, Feng L, Zhao GQ and Dong ZM: HAX-1 promotes the chemoresistance, invasion, and tumorigenicity of esophageal squamous carcinoma cells. Dig Dis Sci 57: 1838-1846, 2012.

113. Wei XJ, Li SY, Yu B, Chen G, Du JF and Cai HY: Expression of HAX-1 in human colorectal cancer and its clinical significance. Tumour Biol 35: 1411-1415, 2014.

114. Li WB, Feng J, Geng SM, Zhang PY, Yan XN, Hu G, Zhang CQ and Shi BJ: Induction of apoptosis by Hax-1 siRNA in melanoma cells. Cell Biol Int 33: 548-554, 2009.

115. Banerjee A, Saito K, Meyer K, Banerjee S, Ait-Goughoulte M, Ray RB and Ray R: Hepatitis $\mathrm{C}$ virus core protein and cellular protein HAX-1 promote 5-fluorouracil-mediated hepatocyte growth inhibition. J Virol 83: 9663-9671, 2009.

116. Janowska-Wieczorek A, Wysoczynski M, Kijowski J, MarquezCurtis L, Machalinski B, Ratajczak J and Ratajczak MZ: Microvesicles derived from activated platelets induce metastasis and angiogenesis in lung cancer. Int J Cancer 113: 752-760, 2005.

117. Soldevilla B, Rodríguez M, San Millán C, García V, FernándezPeriañez R, Gil-Calderón B, Martín P, García-Grande A, Silva J, Bonilla F, et al: Tumor-derived exosomes are enriched in $\Delta \mathrm{Np} 73$, which promotes oncogenic potential in acceptor cells and correlates with patient survival. Hum Mol Genet 23: 467-478, 2014.

118. Yu X, Wei F, Yu J, Zhao H, Jia L, Ye Y, Du R, Ren X and Li H: Matrix metalloproteinase 13: A potential intermediate between low expression of microRNA-125b and increasing metastatic potential of non-small cell lung cancer. Cancer Genet 208: 76-84, 2015

119. Hadler-Olsen E, Fadnes B, Sylte I, Uhlin-Hansen L and Winberg JO: Regulation of matrix metalloproteinase activity in health and disease. FEBS J 278: 28-45, 2011.

120. Radisky ES and Radisky DC: Matrix metalloproteinase-induced epithelial-mesenchymal transition in breast cancer. J Mammary Gland Biol Neoplasia 15: 201-212, 2010. 
121. Hwang BM, Chae HS, Jeong YJ, Lee YR, Noh EM, Youn HZ, Jung SH, Yu HN, Chung EY and Kim JS: Protein tyrosine phosphatase controls breast cancer invasion through the expression of matrix metalloproteinase-9. BMB Rep 46: 533-538, 2013.

122. Balbín M, Pendás AM, Uría JA, Jiménez MG, Freije JP and López-Otín C: Expression and regulation of collagenase-3 (MMP-13) in human malignant tumors. APMIS 107: 45-53, 1999.

123. Sedighi M, Aledavood SA, Abbaszadegan M, Memar B, Montazer M, Rajabian M and Gholamin M: Matrix metalloproteinase-13: A potential biomarker for detection and prognostic assessment of patients with esophageal squamous Cell Carcinoma. Asian Pac J Cancer Prev 17: 2781-2785, 2016.

124. Vairaktaris E, Yapijakis C, Nkenke E, Serefoglou ZC, Chatzitheofylaktou A, Vassiliou S, Derka S, Vylliotis A, Perrea D, Neukam FW, et al: A metalloproteinase-13 polymorphism affecting its gene expression is associated with advanced stages of oral cancer. Anticancer Res 27: 4027-4030, 2007.
125. González-Arriaga P, López-Cima MF, Fernández-Somoano A, Pascual T, Marrón MG, Puente XS and Tardón A: Polymorphism $+17 \mathrm{C} / \mathrm{G}$ in matrix metalloprotease MMP8 decreases lung cancer risk. BMC Cancer 8: 378, 2008.

126. Li Y, Jia JH, Kang S, Zhang XJ, Zhao J, Wang N, Zhou RM, Sun DL, Duan YN and Wang DJ: The functional polymorphisms on promoter region of matrix metalloproteinase-12, -13 genes may alter the risk of epithelial ovarian carcinoma in Chinese. Int J Gynecol Cancer 19: 129-133, 2009.

127. Fan Y, Gan Y, Shen Y, Cai X, Song Y, Zhao F, Yao M, Gu J and $\mathrm{Tu} \mathrm{H}$ : Leptin signaling enhances cell invasion and promotes the metastasis of human pancreatic cancer via increasing MMP-13 production. Oncotarget 6: 16120-16134, 2015. 